Thorax (1974), 29, 659.

\title{
Pulmonary calcification following smallpox handler's lung
}

\author{
P. J. $\operatorname{ROSS}^{1}$, A. SEATON ${ }^{1}, H . M . F O R E M A N^{1}$, \\ and W. H. MORRIS EVANS ${ }^{2}$ \\ Regional Respiratory Centre, Sully Hospital, Cardiff ${ }^{1}$ and Chest Clinic Bridgend, Glamorgan ${ }^{2}$
}

\begin{abstract}
Ross, P. J., Seaton, A., Foreman, H. M., and Morris Evans, W. H. (1974). Thorax, 29, 659-665. Pulmonary cakcification following smallpox handler's lung. A follow-up study of six nurses who developed smallpox handler's lung during the 1962 South Wales smallpox epidemic and of the surviving smallpox patients is reported. The development of extensive punctate calcification in the chest radiographs of five of the nurses, together with the absence of abnormalities of lung function, is taken to support the view that the disease is a modified smallpox pneumonia rather than an allergic alveolitis.
\end{abstract}

A pneumonic illness occurring in vaccinated close contacts of smallpox patients was reported by Chadwick (1843) and has been described more recently by Howat and Arnott (1944) and Ratner and Khudyakova (1962).

Morris Evans and Foreman (1963) described several cases of the 'illness of contact' in nursing volunteers during the South Wales smallpox outbreak of 1962. They postulated that this was a pulmonary hypersensitivity reaction comparable to farmer's lung due to the inhalation of variola virus or scale dust from patients.

We report a follow-up of six of these nurses with smallpox handler's lung and of 10 surviving smallpox patients who did not develop pulmonary symptoms.

\section{SUBJECTS}

Thirty-two volunteer nurses had been involved in the care of 54 patients with smallpox in three isolation hospitals in South Wales in 1962. Of these nurses, 12 had developed pulmonary symptoms, five showing radiographic changes. This report records details of the follow-up of six of these nurses. Their ages in 1962 ranged from 38 to 50 years.

In addition, 12 patients with mild smallpox who had chest radiographs towards the end of their illness were recalled for repeat radiographs as part of the study. Two further surviving patients, who had not had chest radiographs in 1962 , were also recalled.

\section{METHODS}

Standard six-foot postero-anterior chest radiographs were taken during the initial illness and at intervals afterwards. Radiographs taken before the illness were also available for all the nurses.

Radiographs were read in random order by two independent observers and classified according to the presence and type of peripheral opacities. Particular note was made of the distribution and size of the lesions and of the presence or absence of calcification.

Lung function tests were carried out in four nurses in 1962, in one in 1968, and in four in 1974. These tests included spirometry, using a lightweight waterless spirometer, lung volumes by the closed-circuit helium dilution technique, and carbon monoxide transfer factor by the single-breath technique. Predicted normal values were those of Cotes (1968).

Immunological testing for precipitating antibody to vaccinia virus, budgerigar, pigeon and canary serum and droppings, Micropolyspora faeni, Thermoactinomyces vulgaris, 'Air-conditioner pneumonitis' organism, A ureobasidium pullulans, Candida albicans, house dust, and feathers was carried out by the Ouchterlony double diffusion technique.

\section{CLINICAL FEATURES AND RESULTS}

ORIGINAL ILLNESS IN THE NURSES Typically, this began with progressive malaise nine to 12 days after the first exposure to a smallpox patient. This was followed four to six hours later by frontal headache, shivering, sweating, and generalized aching, especially in the lumbar area. The symptom-complex was described as 'influenza-like' but without the catarrhal features.

Some developed a dry irritating cough within three to four days with physical signs of prolonged expiration and scanty crepitations. Three 
developed skin rashes, two resembling erythema multiforme and one with a diffuse erythematous flush. The febrile state lasted from three to 10 days and was intermittent for two to three days.

Of those with symptoms, five showed definite radiological lung abnormalities, three with marked changes. These three complained of slight exertional dyspnoea for a further six to eight weeks.

SYMPTOMS ON FOLLOW-UP (1974) There was no history suggesting a past episode of varicella pneumonia in any of the nurses interviewed. One (No. 4) had been treated for pulmonary tuberculosis in October 1962, approximately five months after the episode of smallpox handler's lung. She reported mild dyspnoea on effort together with intermittent cough productive of white sputum in the last four or five years. She smoked 20 cigarettes daily. Two others (Nos. 1 and 2) reported recurrent winter cough of ten productive of purulent sputum. One of these had smoked for many years. Apart from No. 4 none reported any dyspnoea or symptoms of significant airways obstruction.

RADIOGRAPHY The two readers' reports of the presence and type of parenchymal shadowing were identical in all films.

The chest radiographs of five nurses taken before the acute illness of 1962 showed no significant abnormality. The sixth showed evidence of calcified tuberculosis in both upper lobes and left hilar glands.

Radiographs taken during the acute illness of 1962 in five nurses showed nodular opacities. These varied in size from $2-3 \mathrm{~mm}$ (Nos. 2 and 3 ) to 5-10 mm (Nos. 4, 5, and 6). They were of low density, poorly defined, and distributed mainly in the upper and middle zones (Figs 1 and 2).

The radiograph of nurse No. 1 showed no significant abnormality, either during the illness or on follow-up. Serial chest radiographs in the other five nurses showed the subsequent appearance of diffuse nodular opacities $1-3 \mathrm{~mm}$ in size. These were of high density (calcified), sharply defined, and evenly distributed throughout both lung fields (Figs 3, 4, and 5).

The time interval before calcification appeared varied between four and seven years (Table I). No relationship was noted between the size of the original 'acute' nodules and the size or time of appearance of the calcified nodules.

Follow-up chest radiographs of eight surviving smallpox patients taken in 1974 showed no change from those taken at the time of discharge fromo hospital in 1962. No calcification occurred in theseo radiographs or in those of the two other surviving $\frac{\bar{s}}{\vec{a}}$ patients not previously radiographed.

LUNG FUNCTION The results of lung function testscarried out are shown in Table II. There were no. significant abnormalities found in 1962. Three of $\vec{\omega}$ the four tested in 1974 were smokers and showed evidence of mild airways obstruction. A decreased $\overrightarrow{\vec{x}}$ transfer factor was noted in nurse No. 4 whoi smoked 20 cigarettes daily and had suffered fromos pulmonary tuberculosis in the past.

IMMUNOLOGY No precipitating antibodies to vac- 글 cinia virus, Micropolyspora faeni, Thermoactino- $\vec{Z}$ myces vulgaris, Aurobasidium pullu!ans, Candida@ albicans, house dust or feathers were found in $\frac{\Phi}{3}$ 1962 or 1974. In addition, no precipitating anti-ర్థ bodies to budgerigar, pigeon, and canary serum $\stackrel{\mathbb{}}{-}$ and droppings or 'air-conditioner pneumonitis' organism were detected in 1974.

\section{DISCUSSION}

Howat and Arnott (1944) reported an acute benign pneumonic illness in seven military hospi-气ू tal staff who had been in contact with smallpox $\propto$ patients in the Middle East. Symptoms of increas- $\overrightarrow{\overrightarrow{0}}$ ing malaise, headache, general aching, chills, and 3 sweating developed 11 to 14 days after first con-? tact with a patient. Cough was infrequent and? unproductive, and appeared only after several days. Rash was absent. The febrile state lasted음 four to 12 days. Some crepitations were noted on $\ddot{x}$ auscultation. Radiological changes of fine diffuse $\frac{\sigma}{3}$ mottling, usually in the lower lobes, and rounded opacities in the middle and lower zones were seen $\frac{\rho}{3}$ in six cases from the third day, and in two these persisted for six weeks. These authors considered $\mathrm{O}$ the illness to be due to either modified variola $\frac{D}{2}$ or a virus of unknown origin.

Ratner and Khudyakova (1962) described an episode of fever and chest pain lasting up to four days in three vaccinated contacts of smallpox $N$ patients. This illness developed nine to 15 days $\underset{\omega}{ }$ after first contact. Chest radiographs showed single or several opacities which persisted up to eight months. No skin rashes were noted. They proposed the term 'pulmonary form' of smallpox ?

to describe the illness.
In the cases we have studied, it is considered $\frac{0}{\overrightarrow{0}}$ very unlikely that the illness was due to coincident $\stackrel{?}{\mathbb{P}}$ virus, fungal or bacterial infection. This is indi- $\stackrel{D}{\varrho}$ cated by the negative viral agglutination tests and 


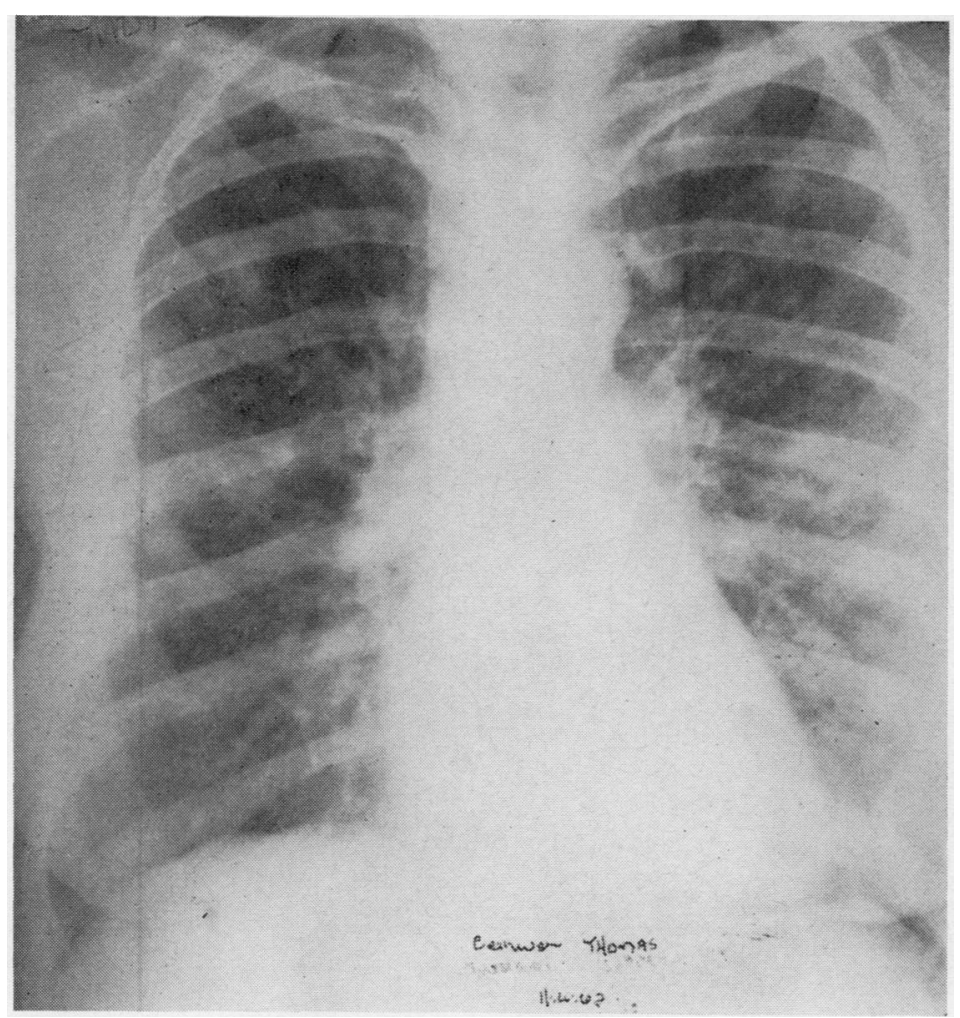

FIG. 1. Chest radiograph of nurse No. 5 taken during the acute illness, showing patchy low-density infiltrates predominantly in the upper and mid zones.

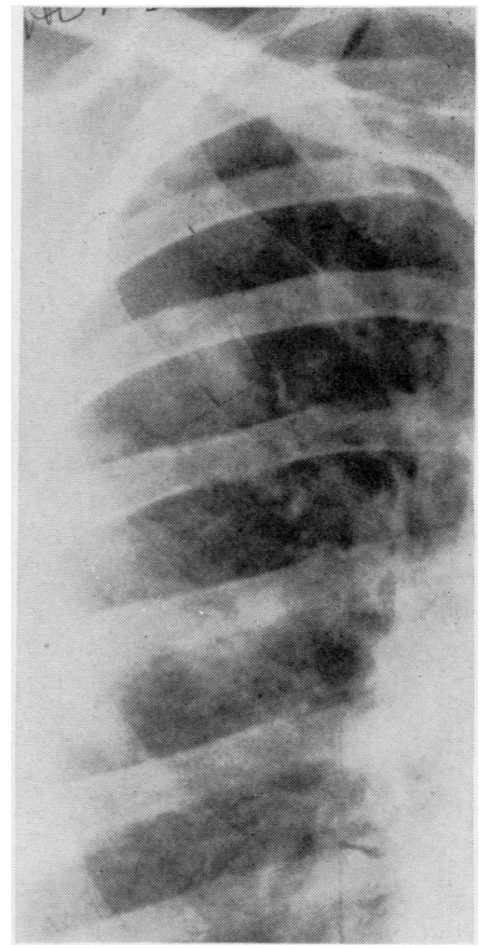

FIG. 2. Close-up view of the same radiograph as in Fig. 1 showing detail of the opacities. examination of sputum carried out during the acute illness by Morris Evans and Foreman (1963). The affected nurses were working in separate isolation hospitals and there was no clinical history to suggest varicella pneumonia, Histoplasma infection, or miliary tuberculosis.

Morris Evans and Foreman (1963) commented at that time that actual invasion of the lung by the variola virus had never been proved and there was then no epidemiological evidence that this type of lung lesion was infectious. They therefore suggested the changes might have been due to a hypersensitivity reaction in the lungs of the nurses. The nature of the antigen was not certain but was thought to be the variola virus inhaled in droplets or scale dust from the patients during activities such as routine bed making.

The 'illness of contact' they and others described had previously been considered to be a highly modified smallpox infection, and in this

\section{T A B L E I}

SERIAL RADIOLOGY OF SIX NURSES WITH SMALLPOX HANDLER'S LUNG

\begin{tabular}{|c|c|c|c|c|c|c|c|c|c|c|c|c|c|c|}
\hline Nurse & Pre-1962 & 1962 & 1963 & 1964 & 1965 & 1966 & 1967 & 1968 & 1969 & 1970 & 1971 & 1972 & 1973 & 1974 \\
\hline $\begin{array}{l}1 \\
2 \\
3 \\
4 \\
5 \\
6\end{array}$ & $\begin{array}{l}\text { NC } \\
\text { NC } \\
\text { NC } \\
\text { NC } \\
\text { NC } \\
\text { NC }\end{array}$ & $\begin{array}{l}\mathbf{N C} \\
\mathbf{N C} \\
\mathbf{N C} \\
\mathbf{N C} \\
\mathbf{N C} \\
\mathbf{N C}\end{array}$ & $\begin{array}{l}\mathrm{NC} \\
\mathrm{NC} \\
\mathrm{NC} \\
\mathrm{NC}\end{array}$ & $\begin{array}{l}\mathrm{NC} \\
\mathrm{NC} \\
\mathrm{NC}\end{array}$ & $\begin{array}{l}\text { NC } \\
\text { NC } \\
\text { NC }\end{array}$ & $\begin{array}{l}\mathrm{NC} \\
\mathrm{NC}\end{array}$ & $\begin{array}{l}\underset{\mathrm{NC}}{\mathrm{NC}} \\
\mathrm{EC}\end{array}$ & $\begin{array}{c}\mathrm{NC} \\
\mathrm{C} \\
\mathrm{C}\end{array}$ & $\begin{array}{c}\text { EC } \\
C\end{array}$ & $\begin{array}{l}\mathbf{C} \\
\mathbf{C} \\
\mathbf{C} \\
\mathbf{C} \\
\mathbf{C}\end{array}$ & $\begin{array}{l}\mathrm{C} \\
\mathrm{C}\end{array}$ & C & $\begin{array}{l}\mathrm{C} \\
\mathrm{C}\end{array}$ & $\begin{array}{c}\mathrm{NC} \\
\mathbf{C} \\
\mathbf{C} \\
\mathbf{C}\end{array}$ \\
\hline
\end{tabular}

C-multiple calcified nodules seen on chest radiograph; NC-no calcification seen on chest radiograph; EC-early evidence of calcification in some lesions. 


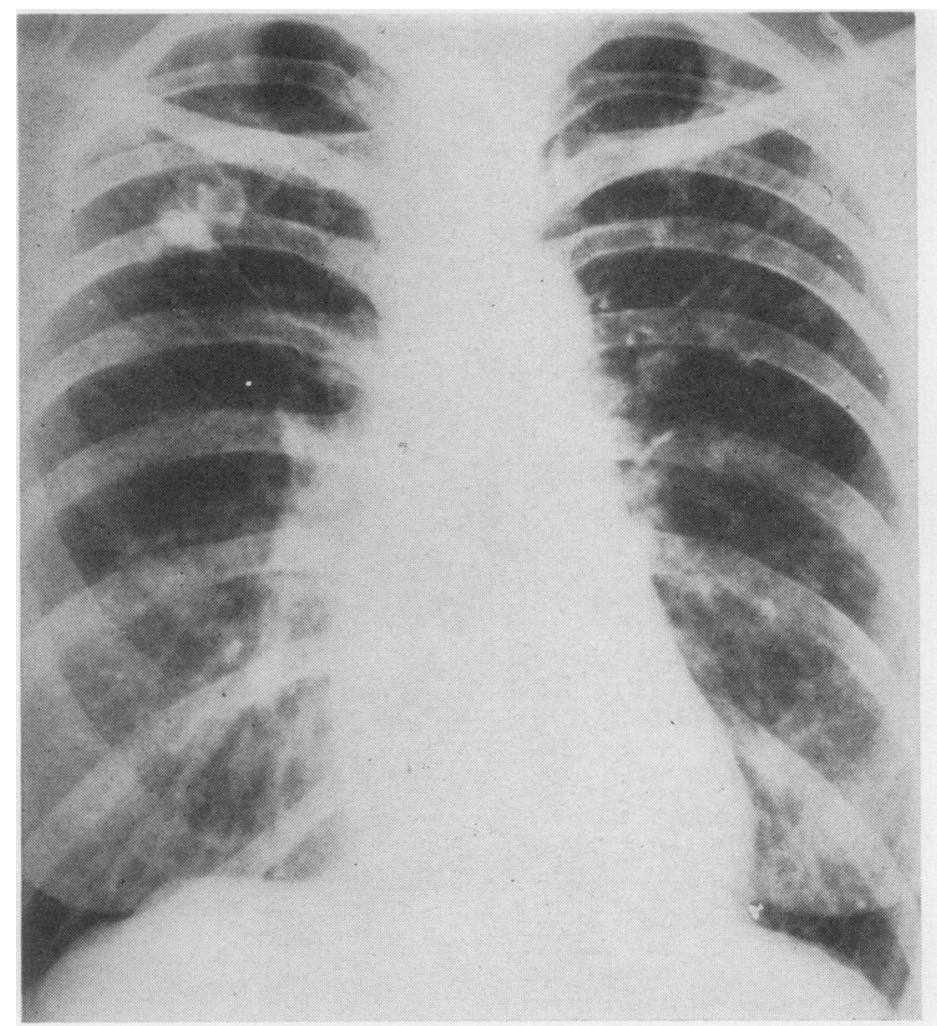

FIG. 3. Radiograph taken during the acute illness in nurse No. 4, showing nodular opacities in upper zones and calcified lesions of healed tuberculosis.

respect the erythematous rashes observed in three of our cases are interesting. They are seen as a prodromal manifestation of about $10 \%$ of all smallpox cases and are said to occur almost exclusively in the partially immune patient whose illness tends to run a benign course (Ricketts and Byles, 1908). There are several features of the acute illness which are unlike an allergic reaction such as farmer's lung. Dyspnoea was not a marked feature. There was no increase in serum gamma-globulin, and detailed studies of lung function performed while the lung lesions persisted were normal, in contrast to those seen in an allergic reaction such as farmer's lung where a restrictive defect with reduced transfer factor is commonly found (Hapke et al., 1968).

The initial radiographic lesions in our nurses appeared to be of two types. One, occurring in three nurses, was of a larger, blotchy, 'alveolar filling' lesion, while the other was of a smaller, interstitial type of nodularity. It is possible, however, that these represented two stages of the same process as both evolved in an identical man- ner over succeeding years. The most interesting feature on serial radiology was the appearance, 0 after an interval of five or six years, of widespread punctate calcification. We know of no reference to calcification as a late feature of allergic alveoli- 3 tis, but it is a well-known complication in sur- o $^{\circ}$ vivors of varicella pneumonia (Mackay and3 Cairney, 1960; Abrahams, Evans, Knyvett, ando Stringer, 1964). Although the viruses of varicella? and variola are structurally different the tissueo reactions are known to be closely similar (Cappell and Anderson, 1971). This calcification is stronglyos suggestive of an infection by the inhaled variolan virus.

The failure to grow variola virus from the sputum, nasopharyngeal washings, or skin scrapings of the rash from three of the nurses in 1962 may well have been due to the scarcity of the virus inc? the specimens and its modification by the defence mechanisms of the highly vaccinated host. More-o over, it is curious that none of the patients who survived the disease developed similar lung lesions. $\frac{}{\mathrm{D}}$ The differences between the nurses and the $\frac{\varrho}{\sigma}$ 
FIG. 4. Radiograph of the same subject as in Fig. 3 taken in 1974, showing the presence of miliary calcification in addition to that due to old tuberculosis.
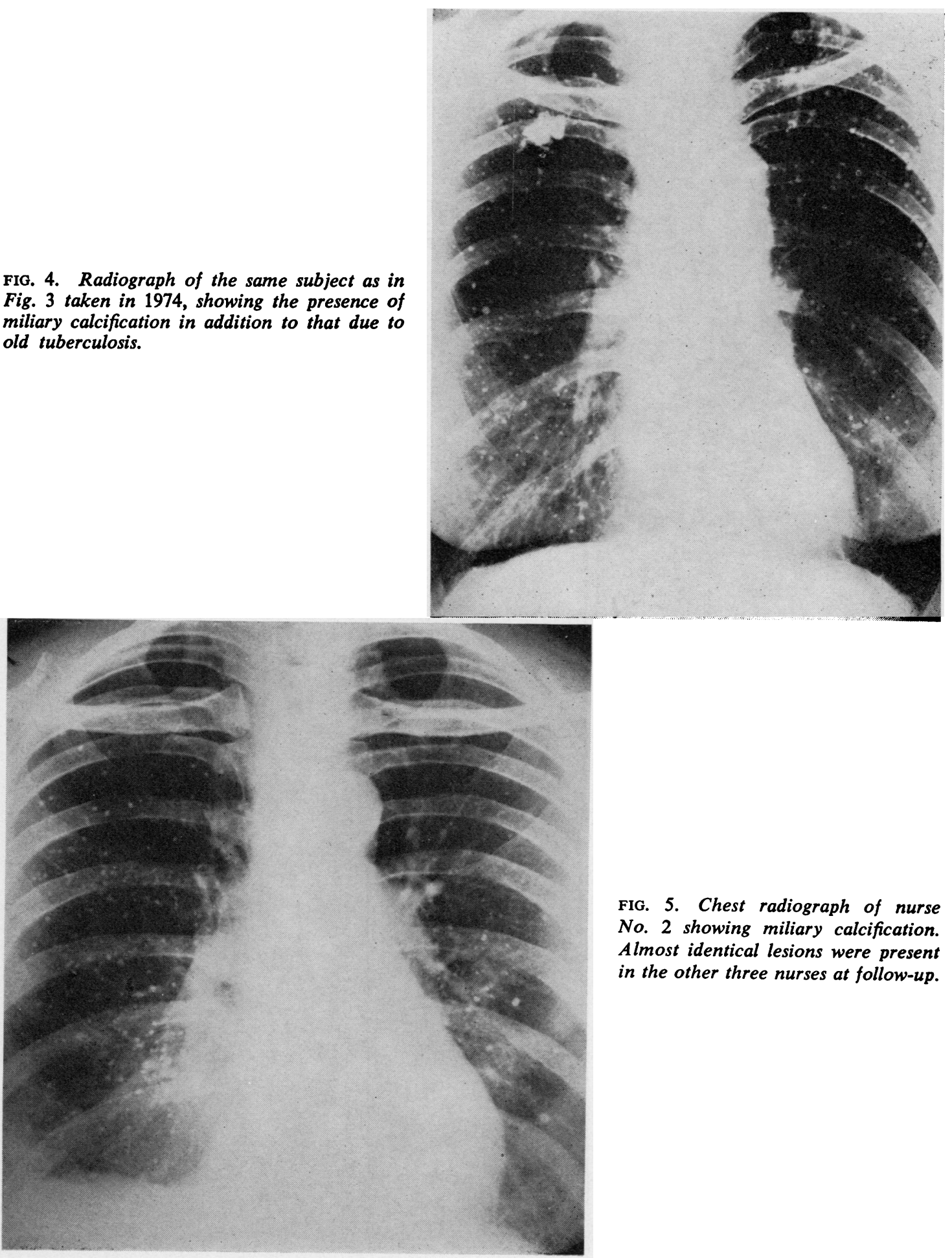

FIG. 5. Chest radiograph of nurse No. 2 showing miliary calcification. Almost identical lesions were present in the other three nurses at follow-up. 


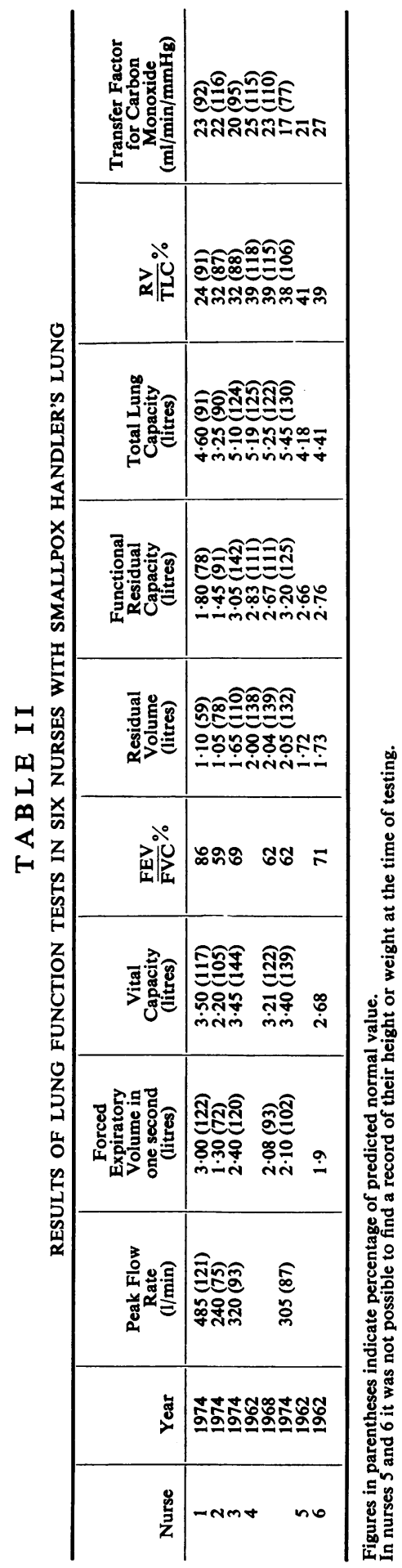


patients must be explained by differences in the numbers of virus particles, the nurses presumably inhaling many more than any individual patient, and their different immunization status prior to exposure. It seems likely that smallpox handler's lung, a disease showing closely similar features in the three published reports, is a modified pulmonary infection with variola virus in highly immune subjects.

We are grateful to Dr. J. C. Meek for an independent reading of the radiographs, to Dr. J. E. Cotes for the original lung function testing, and to Miss P. Edwards for typing the manuscript.

\section{REFERENCES}

Abrahams, E. W., Evans, C., Knyvett, A. F., and Stringer, R. E. (1964). Varicella pneumonia: a possible cause of subsequent pulmonary calcification. Medical Journal of A ustralia, 2, 781.

Cappell, D. F. and Anderson, J. R. (1971). Muir's Textbook of Pathology, 9th ed. Edward Arnold, London.

Chadwick, E. (1843). Report on the sanitary condition of the labouring population of Great Britain:
Supplementary report on the practice of interment in towns. HMSO, London.

Cotes, J. E. (1968). Lung Function (Assessment and Application in Medicine), 2nd ed. Blackwell Scientific Publications, Oxford.

Hapke, E. J., Seal, R. M. E., Thomas, G. O., Hayes, M., and Meek, J. C. (1968). Farmer's lung: a clinical, radiographic, functional, and serological correlation of acute and chronic stages. Thorax, 23, 451 .

Howat, H. T. and Arnott, W. M. (1944). Outbreak of pneumonia in smallpox contacts. Lancet, 2,312 .

Mackay, J. B. and Cairney, P. (1960). Pulmonary calcification following varicella. The New Zealand Medical Journal, 59, 453.

Morris Evans, W. H. and Foreman, H. M. (1963). Smallpox handler's lung. Proceedings of the Royal Society of Medicine, 56, 274.

Ratner, S. I. and Khudyakova , G. K. (1962). On the pulmonary form of smallpox. Klinika Medika, 40, 51 .

Ricketts, T. F. and Byles, J. B. (1908). The Diagnosis of Smallpox. Cassell, London.

Requests for reprints to: Dr. A. Seaton, Sully Hospital, Sully, Penarth, Glamorgan CF6 2YA. 